\title{
De arabiske jødene
}

Før opprettelsen av Israel i 1948 var det omlag 870000 jøder som levde som religiøse minoriteter i Midtøsten. Den nye staten Israel representerte ikke bare et "nytt hjemland" for de overlevende etter Holocaust, men også et hjemland for de jødiske migrantene fra NordAfrika og Midtøsten. Et av verdenshistoriens største og mest omfattende migrasjonsprosjekter skulle få drastiske konsekvenser for jøder fra denne regionen. 
TEKST: Cathrine Furberg Moe

DENNE ARTIKKELEN OMHANDLER rollen jøder har hatt som religiøs minoritet $\mathrm{i}$ Midtøsten under muslimsk styre, og den nye rollen de ble tildelt som etnisk minoritet i sitt "nye hjemland". I Israel var institusjonene og idealene om den "nye jøde” allerede formet av den europeiske sionistbevegelsen, uten rom for en arabiskjødisk erfaringsverden. Jødene fra Midtøsten $^{\text {I }}$ (mizrahim) befinner seg i en paradoksal minoritetstatus i Israel på grunn av sin ikke-europeiske bakgrunn. ${ }^{2}$ Majoriteten av disse har likevel alliert seg med den ashkenazi-dominerte jødiske staten, og ikke med palestinere som de deler mange sosioøkonomiske og kulturelle trekk med. Mangfoldet av Israels jødiske samfunn og historie blir ofte redusert til et europeisk narrativ i den dominante sionistiske diskursen. I dag blir denne utfordret av aktivister og akademikere som synliggjør den komplekse historien og vedvarende diskrimineringen mizrahim fortsatt opplever i Israel.

\section{Dhimmi-systemet}

Den jødiske eksistens i hva vi i dag omtaler som den arabiske verden startet rundt år 597 f. Kr, med det babylonske fangenskapet. Jødenes status og situasjon som religiøs minoritet $\mathrm{i}$ arabiske og muslimske land har variert $i$ takt med tid og sted. Historisk sett har de hatt det bedre enn jødene som bodde i kristne land i Europa. ${ }^{3}$ Bernard Lewis har hevdet at det var få tegn til en dyp fiendtlighet rettet mot jøder eller andre minoritetsgrupper under muslimsk styre som antisemittismen i den kristne verden. I kontrast til kristen antisemittisme var muslimers holding til religiøse minoriteter preget av en generell nedsettende holdning, og ikke hat, frykt eller misunnelse.

Under muslimsk styre ble jødene sammen med andre minoritesgrupper styrt av lover basert på sharia'a, eller islamsk hellig lov. Det gikk en klar skillelinje mellom troende og vantroende, men jødene tilhørte en tredje kategori sammen med kristne, "bokens folk" (ahl al-kitab) eller "beskyttede folk" (ahl al-dhimma, eller dhimmis). Kristne og jøder med dhimmistatus tror på den samme guden som muslimene, og kan derfor ikke konverteres mot sin vilje. De fikk beskyttelse og toleranse under muslimsk lov og overherredømme, men hadde en annenrangs rettslig og sosial status.

Implementering og tolkning av dhimmilovene ble påvirket av teologisk rammeverk, økonomiske faktorer og politisk kontekst. ${ }^{4}$ Jødene hadde derfor et ambivalent forhold til den muslimske befolkningen, 
både preget av en stor grad av samhandling og en sammenfallende tendens til å unngå kontakt. Historisk opplevde de et vekslende forhold mellom kulturell og økonomisk velstand, og en innsnevring av rettigheter. Noen perioder var preget av toleranse hvor jødene kunne leve relativt trygt og rolig. I de seks første århundrene av islam, referert til som "den gylne epoke", levde jødene relativt trygt og var involvert i kulturell og økonomisk samhandling med sine muslimske naboer. Dette var i sterk kontrast til flere land i det kristne Europa hvor jødene var marginalisert fra storsamfunnet. Likevel, hvis jødenes posisjon i Midtøsten ble oppfattet som for "komfortabel" kunne dhimmi-systemet slå over i forfølgelse.

Som annenrangs innbyggere med dhimmistatus måtte jøder og kristne følge visse restriksjoner. Lewis viser flere eksempler på dhimmireguleringer som symboliserte deres underlegenhet som religiøs minoritet. De måtte blant annet betale en årlig eiendomsskatt (kharaj). Under den osmanske perioden kunne verken jøder eller kristne gi barna sine navn som ble brukt av muslimer. Som ikke-muslimer kunne de heller ikke røre koranen, snakke nedsettene om Profeten eller gifte seg med muslimske kvinner. Her følger noen av de historiske erfaringene til jødiske samfunn i to vidt ulike land, Marokko og Jemen.

\section{Jødene i Marokko og Jemen (før I948)}

Jøder har bodd i Marokko i minst 2000 år og vært hjem til det største jødiske samfunn i et muslimsk land. De jødiske samfunnene var ofte semi-autonome enheter som ble styrt av ledere som hadde ansvaret for relasjonene til de muslimske styresmaktene.7 Til tross for dhimmi-reguleringer var jødene dypt involvert i nesten alle deler av samfunnet som stort sett var preget av toleranse og samhandling. I tillegg til religiøse studier av bibelen og talmud, deltok flere aktivt i utformelsen av marokkansk poesi og filosofi. De hadde også utstrakte internasjonale forbindelser gjennom kontakt med andre jødiske samfunn både i Europa og den arabiske verden.

Under den spanske inkvisisjonen på I500- og I6oo-tallet flyktet jøder fra Spania og Portugal til Nord-Afrika. I I492 utstedte kong Ferdinand og dronning Isabella et utvisningsedikt for jøder som ikke hadde

\section{Jødene fikk beskyttelse og toleranse under muslimsk lov, men hadde en annenrangs sosial og rettslig status.}

latt seg døpe. Mer enn 200 ooo jøder ble utvist fra Spania, og flere tusen døde under denne prosessen. Den plutselige tilstrømmingen av immigranter til Marokko skapte overbefolkning i de større byene og førte til spenninger. De nyankomne immigrantene livnærte seg på håndverk og handel, og den muslimske majoriteten fryktet at prisene ville øke. Under slike anstrengte perioder ble dhimmi-regler strengere håndhevet. Hvis jødene skulle bevege seg utenfor det segregerte boligområdet, mellahen, måtte de gå barfot eller med stråsko som en synlig markør på sin annenrangs status. ${ }^{8}$

De marokkanske jødene utviklet også nære bånd til berberne, et ikke-arabisk muslimsk samfunn. Blant berberske og marokkanske jødiske samfunn i Atlasfjellene var det sterke og gjensidige kulturelle, religiøse og økonomiske bånd. Berbersk folketro påvirket jødiske ritualer, og særlig 
troen på makten til demoner og helgener. ${ }^{9}$ Mimunah-festivalen $^{\text {1o }}$ og den jødiskmarokkanske helgentilbedelsen er to fremtredende kulturelle tradisjoner som eksemplifiserer sammenflettingen av tradisjoner i Marokko. Mimunah feires umiddelbart etter jødisk påske (pessach), og er en hyllest av fruktbarhet og gavmildhet. I Marokko var også muslimer en integrert del av denne rike, kulturelle begivenheten. Jøder og muslimer utvekslet festmat på kvelden som ble antatt for å ha magiske kvaliteter. Muslimene leverte den tabubelagte ingrediensen hvete når den hellige uken var slutt, og fikk mat fra påskemåltidet i gjengjeld. Heller ikke helgentilbedelse var en unik jødisk praksis som muslimer tok del i som annenrangs deltagere, men en av de fremste identitetsmarkørene for begge gruppene. Graver til helgener (tzazzikim) ${ }^{\text {II }}$ i Marokko blir fortsatt ansett for å være hellige steder både for jøder og muslimer. ${ }^{\mathrm{I2}}$ Jødedommen som blir praktisert i dagens Marokko er en fusjon av berberske, arabiske og spanske tradisjoner. $^{13}$

De jemenittiske jødene eksisterte kontinuerlig som minoritet $\mathrm{i}$ over $\mathrm{I} 500$ år fra midten av 500-tallet fram til de immigrerte til Israel. I motsetning til jødene i Marokko, levde de relativt isolert, og de beholdt en distinkt religiøs, kulturell og etnisk identitet i kontrast til sine omgivelser. Jemenittiske jøder var spredt utover hele landet, men de største samfunnene var konsentrert i Aden, Sana'a, Dhamar og Beda-ørkenen. Som hos mange andre minoriteter $\mathrm{i}$ Midtøsten var deres situasjon påvirket av politiske omstendigheter, og relasjonene til den muslimske majoriteten var komplekse og paradoksale. På den ene siden var de beskyttet av imamen (ingen fikk utøve vold mot en jøde, og straffen for å rane en jøde var mye høyere enn for å rane en ikkejøde), og mange jøder hadde viktige økonomiske posisjoner i samfunnet. På den annen siden måtte de også her innordne seg etter dhimmi-reguleringer. Synagogene kunne ikke være høyere enn den laveste moskeen i området, og jødene måtte følge restriksjoner for bekledning, hårfrisyre, eierskap og giftermål. ${ }^{14}$

Fra midten av I80o-tallet fikk europeiske stormakter med Storbritannia og Frankrike i spissen kontrollen over mesteparten av den arabiske verden. Dhimmireglene opphørte flere steder under kolonitiden, men i daværende NordJemen som ikke ble kolonialisert fortsatte reglene å gjelde fram til jødenes masseimmigrasjon til Israel. ${ }^{\text {I5 }}$

\section{Masseemigrasjon}

Både jøder fra Marokko og Jemen ble ansett som et viktig ledd i nasjonsbyggingen i årene etter opprettelsen av Israel. Gjennom masseutvandring og storstilte immigrasjonsbølger ble de arabiske jødene forsøkt assimilert inn i det sionistiske europeisk-jødiske bildet. Den nasjonale konflikten tvang de arabiske jødene inn i det offisielle konstruerte minnet av europeiske jøder mot deres palestinske rivaler.

På slutten av I940-tallet ble situasjonen til jødene forverret som et resultat av en økende arabisk nasjonalisme grunnet europeisk okkupasjon, nazismens popularitet i Nord-Afrika og konflikt i det britiske mandatet i Palestina. Den europeiske sionismens fremvekst $i$ det palestinske mandatet og en stigende innvandring gjorde at enhver arabisk-jødisk sympati for etablering av et jødisk hjemland i Palestina ble 
tolket som et brudd på dhimmi-lovene. Dette førte til en uholdbar situasjon for flere jødiske samfunn i Midtøsten. Etter oppretteslen av Israel i I948 og påfølgende arabisk-jødiske spenninger, ble rundt 49 o०o jøder fra Jemen fraktet med fly til Israel via Aden i en hemmelig operasjon som ble omtalt som "det flygende teppet". ${ }^{16}$ I dagens Jemen er det kun noen få tusen jøder igjen, hvorav de fleste bor i nordområdene.

Som en konsekvens av opprettelsen av Israel, slutten på fransk kolonistyre og massiv emigrasjon til både Israel, Frankrike og Kanada, ble den marokkanske jødiske befolkingen drastisk redusert. I toårsperioden fra I955 til I957, emigrerte over too o०० marokkanske jøder, noe som førte store deler av den jødiskmarokkanske befolkningen til Israel. Seksdagerskrigen i I967 medførte økende arabisk-jødiske spenninger verden over, også i Marokko. Innen I97I, var den jødiske befolkningen helt nede i 35 000, selv om disse stort sett dro til Europa og Nord-Amerika og ikke Israel.

I dag har Marokkos jødiske minoritet sunket betraktelig og teller rundt 7000. De fleste bor i Casablanca eller i små samfunn i byer som Fez, Rabat og Marrakech, men det er også eksisterende berber-jødiske landsbyer i Inezgane.

\section{Arabiske jøder i Palestina}

Den moderne sionismen var en bevegelse som hovedsaklig var sekulær og begynte som et svar på den tragiske antisemittismen som spredte seg i Europa i det nittende århundre. Sionismen ble grunnlagt på drømmen om en jødisk, nasjonal enhet og som et svar på “det jødiske spørsmål”. En av sionismens største motivasjoner var at jødene trengte et historisk hjemland som beskyttelse mot antisemittisme og for å samle nasjonen inn i en nasjonalstat. Balfour-deklarasjonen fra I9I7 var et formelt politisk utsagn hvor den britiske regjeringen støttet sionistbevegelsens planer for et jødisk nasjonalt hjem i Palestina. De sionistiske planene ble ikke utelukkende møtt med positiv støtte blant jødene i Midtøsten. Flere av de fremste tenkere i jødiske samfunn i Tyrkia, Irak og Egypt var aktive motstandere av sionismen. Jødene i Istanbul var involvert $\mathrm{i}$ anti-sionistiske aktiviteter samme året som verdens sionistbevegelse ble grunnlagt. ${ }^{17}$

Yusuf al-Kabir, en jødisk advokat fra Baghdad publiserte et brev til Iraqi Times 5. november I938 hvor han hevdet at problemet Balfour-deklarasjonen prøvde å løse var og forble et europeisk problem, og at faktorene som lå bak opprettelsen av bevegelsen var nesten helt fraværende i Midtøsten. ${ }^{18}$

Den tidligste migrasjonen av ikkeeuropeiske jøder til Palestina foregikk mellom I9Io og I9I4. Sionistbevegelsen hadde et par år tidligere foreslått å bruke "hebraisk arbeidsstyrke" (Avodah 'Ivrit), som ble ansett som et viktig fundament for en framtidig jødisk nasjonalstat. Den nye jøde skulle bli bundet til et framtidig Israel som arbeider og soldat. Dette var også hovedprinsippet til Histadrut, arbeidernes organisasjon, som ble grunnlagt i I920. Lokal arabisk arbeidskraft som ble brukt i de tidlige bosettingene (yishuv) ble ansett for å ødelegge sionistiske idealer. Det sosialistiske, sionistiske målet var å avvise religion og diasporamentaliteten blant det jødiske folket. Betegnelsen "diasporamentalitet" ble brukt for å omtale den svake, passive, jøde, det "menneskelige støv, som 


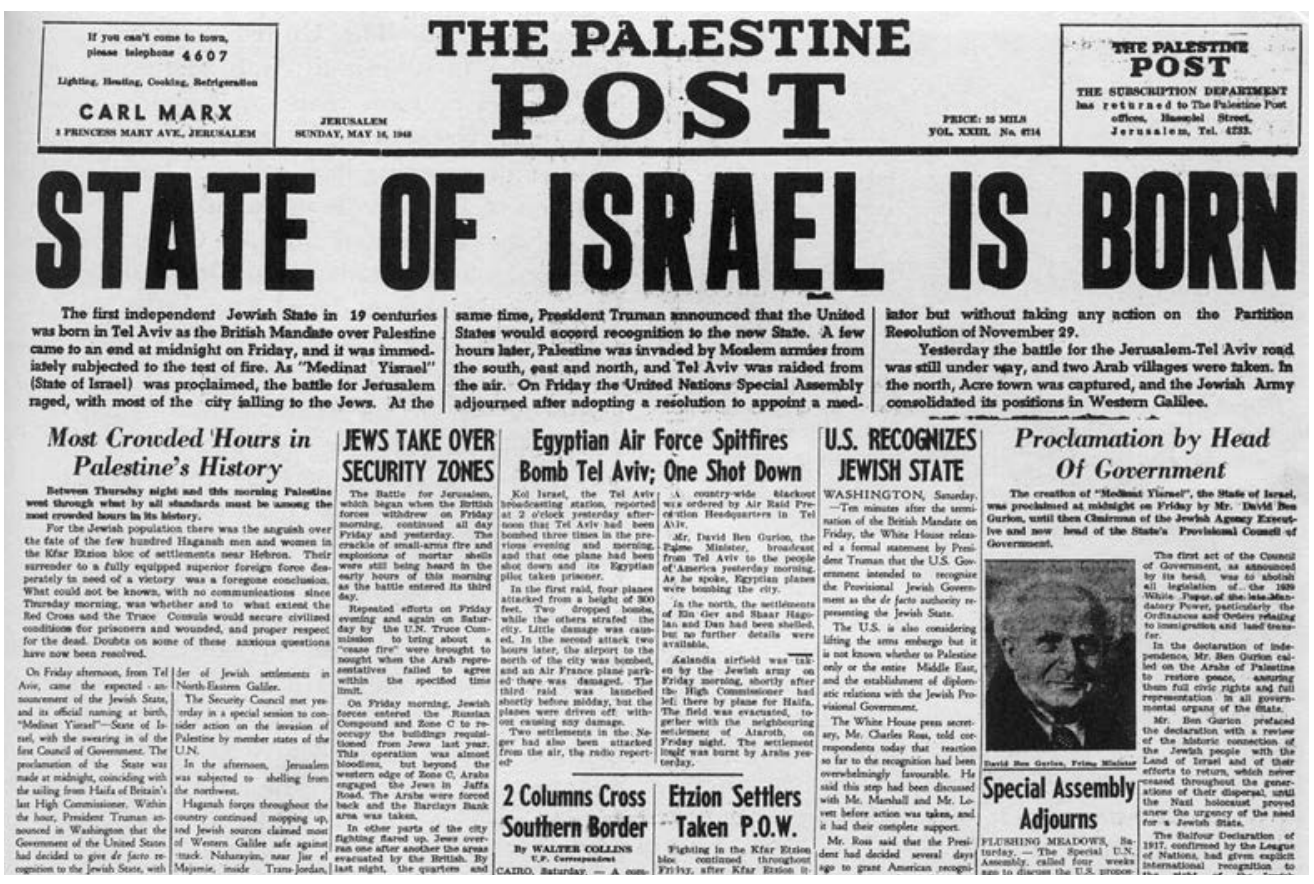

The Palestine Post proklamerer opprettelsen av staten Israel i I948.

utgjorde det jødiske folk". Selv om denne betegnelsen ble rettet mot europeiske jøder, viser den det nedsettende synet på arabiske jøder i den tidlige sionistiske diskursen. Under det britiske mandatet var det en klar hierarkisk rangering blant jøder, hvor jødene fra Midtøsten og Nord-Afrika ble rangert som annenrangs innbyggere. Jødene fra Jemen, Marokko og andre arabiske land, ble stigmatisert som primitive og uvitende. Den revisjonistiske sionistiske lederen Vladimir Jabotinsky uttrykte sin bekymring da han i I926 uttalte; "Jøder, takk Gud, har ingenting til felles med Østen. Vi må sette en stopper for ethvert spor av den orientalske ånd i de innfødte jødene i Palestina." ${ }^{\prime 9}$

Sionistbevegelsen i Palestina foreslo at jemenittiske jøder kunne "erstatte araberne". De ble ansett som ypperlig arbeidskraft siden de var vant med jordbruksarbeid og kunne snakke både arabisk og hebraisk..$^{20}$ På denne tiden utgjorde den palestinske jødiske minoritet kun to prosent av den arabisktalende palestinske befolkningen. I tillegg til jemenittiske og palestinske jøder, ble noen tusen kurdiske og persiske jøder hentet inn for å jobbe. Jemenittene arbeidet under umenneskelige forhold og fikk så dårlig betalt at de knapt kunne brødfø sine familier. Flere ble også bedt om å forlate bosettingene på bakgrunn at de ikke var passende arbeidere. Aha Ha'Am, en anerkjent sionist humanist, bekymret seg over at "Jemenittimmigrasjon ville påvirke naturen til de sionistiske bosetterne med sin kultur og mental-

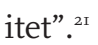

\section{Opprettelsen av Israel}

Det britiske koloniregimet fra I92I til I948, fungerte som et politisk og militært "lokk" hvor sionistbevegelsen utviklet det grunnleggende institusjonelle, økono- 
miske og sosiale rammeverket. Fram til I4. mai I948 hadde 450 ooo jøder immigrert til Israel. 380 ooo fra Europa og 45000 fra Asia og Afrika, eller rundt 22 prosent av den jødiske befolkningen. ${ }^{22}$ Britene trakk seg ut av Palestina I4. mai I948, og dagen etter ble staten Israel proklamert. Innen den tid hadde over 300 ooo palestinere flyktet, og ytterlige 430 ooo ville flykte innen

\section{De arabiske jødene ble forsøkt assimilert inn $i$ det sionistiske europisk-jødiske bildet.}

året var omme. Kun I50 000 palestinere ble værende i territoriene okkupert av Israel i I949. De fleste ødelagte landsbyene falt under områder som ble tildelt den jødiske staten under FNs delingsplan den I4. november I947. ${ }^{23}$

I juli I950 godkjente det israelske parlamentet, Knesset, Loven om retur, som befestet at enhver jøde skulle ha rett til å komme til Israel som immigrant. Daværende statsminister Ben Gurion kalte denne loven for grunnsteinen i Israel ettersom den automatisk gav de nye immigrantene statsborgerskap.

Lovens liberale karakter reflekterte Israels behov for masseimmigrajon som et ledd i nasjonsbyggingen. Den jødiske majoriteten ble styrket mot den arabiske minoriteten ved å tillate flere jødiske immigranter til Israel. Mellom mai I948 og mai I95I, ankom 3I0 ooo immigranter fra arabiske land i kontrast til I76.000 fra Europa, Amerika og Storbritannia. ${ }^{24}$ Ikkeeuropeiske jøder ble klassifisert som sefardi og senere mizrahi (fra Østen) i kontrast til jødene som snakket jiddisk. Palestinerne ble delt inn i druse, beduin, kristne og muslimske arabere. Mizrahim ble hyppig brukt av ikke-europeiske aktivister på I980-tallet, og begynte gradvis å erstatte sefardi, som refererer til etterkommere av de spanske jødiske samfunn. Sefardi blir i dag brukt som betegnelse på jøder fra områdene rundt Middelhavet og fra Midtøsten. ${ }^{25}$ Det er viktig å understreke at både mizrahim, sephardim og ashkenazim har sine interne differensieringer. Kun et fåtall mizrahim i Israel vil i dag omtale seg selv som "arabisk jøde”. Når disse merkelappene brukes er det for å belyse og anerkjenne den komplekse historien og erfaringene til de ikke-europeiske jødene.

\section{Stigmatisering av arabisk kultur og språk}

I Israel var institusjonene allerede etablert og formet av askhenasiske jøder, betegnelsen på jøder fra Europa. De nye immigrantene måtte tilpasse seg de dominerende sionistiske idealer slik de var formulert av Theodor Herzl. I hans syn skulle den "nye jøde" i den jødiske stat ikke være stort annerledes enn den kultiverte europeer; et rasjonelt, liberalt og progressivt individ, et produkt av jødisk assimilasjon i det vesteuropeiske samfunnet. Den nye israelske identitet og kultur var svært fremmed for jøder fra diasporaen. Immigrantene fra Nord-Afrika og Midtøsten måtte likevel tilpasse seg den sekulære jødiske nasjonalstaten, for slik å skape den nye ikke-arabiske jøden. ${ }^{26}$

Sentral for utviklingen av en jødisk, sekulær nasjonal bevissthet var revitaliseringen av hebraisk. Inntil det nittende århundre ble hebraisk stort sett kun brukt i det religiøse domenet. På I880-tallet ble hebraisk modernisert av Eliezer Ben-Yehu- 
da. I begynnelsen ble språket for det meste brukt i litteratur og journalistikk, men med grunnleggelsen av den sionistisk politiske bevegelse, gjennomgikk det en ny lingvistisk revitalisering hvor hebraisk ble ansett som et sentralt symbol i opprettelsen og ivaretakelsen av nasjonal identitet. Ved opprettelsen av Israel i I948, snakket jøder fra hele verden en mengde ulike språk. De arabisktalende immigrantene ble møtt med et dilemma.

Den nye jødiske staten var i krig mot araberne, folket som representerte deres kultur, språk og utseende. På et tidspunkt ble det foreslått at hebraisk som semittisk språk skulle uttalles nærmere arabisk, men Jabotinsky argumenterte for at "Vi er europeere og vår musikalske smak er europeisk, smaken av Rubienstein, Mendelssohn og Bizet." Arabisk ble stigmatisert som språk, og flere ble tvunget til å ta nye, europeiske navn. Jødene fra Midtøsten ble nødt til å distansere seg fra den arabiske kulturen og språket for å bli akseptert av det europeisk-dominerte samfunnet. ${ }^{27}$

I løpet av I950-tallet ble mizrahim plassert i utviklingsbyer og immigrasjonsleire som skulle øke integreringen og “absorbere" jødene inn i det nye israelske samfunnet. Disse bosettingene lå i utkantstrøk i segregerte og fattige områder, og var strategisk viktige for å sikre frontene og de politiske grensene. Målet var å beholde dominansen i Midtøsten, øke den jødiske befolkningen og plassere de nye immigrantene i utkantområder hvor det var en høy konsentrasjon av palestinere. I et dokument fra immigrasjonsorganisasjonen Jewish Agency fra I978 står det at "vi må fortsette å bringe jøder til Galilea og Negev. Det økende antall arabere i denne regionen gir oss kun to muligheter; vi kan la situasjonen utvikle seg naturlig så vi mister disse områdene, eller vi kan videreføre tradisjonen av jødiske bosettinger og redde dem fra arabiske hender.

\section{Sosial protest}

Den klassekulturelle undertrykkelsen har blitt møtt av politisk motstand og aktivisme fra mizrahim. I I959 brøt det ut opptøyer og demonstasjoner i Wadi Salib, et hovedsaklig marokkansk nabostrøk i Haifa. Demonstrantene protesterte mot etnisk diskriminering og mot arbeiderpartiets (Mapai) dominans i Israel på den tiden.

Opprettelsen av Black Panthers på midten av I970-tallet var en annen sterk motreaksjon på den kulturelle og økonomiske diskriminering mizrahim opplevde siden Israels opprettelse. Det var en av de første bevegelsene som kjempet for sosial rettferdighet for mizrahim. Navnet viser en klar bevissthet og sammenligning med afroamerikanernes frigjøringsbevegelse og marxistiske bevegelser i Latin-Amerika. Bevegelsen bidro til å plassere mizrahiundertrykkelsen øverst på den israelske politiske, offentlige og akademiske dagsorden.

Det politiske partiet Likud kom til makten i 1977 med stemmer overveiende fra mizrahim, og markerte slutten på arbeiderpartiet, Mapai, sitt politiske hegemoni. Lederen, Menachem Begin samarbeidet med mange av medlemmene fra "de sorte panterne” for å sikre seg stemmer. På åtti-tallet vitnet opprettelsen av det politiske Shaspartiet om den dype misnøyen blant mizrahim. Partiet oppstod som et motsvar mot det ultraortodokse samfunnet som er åpenlyst rasistisk mot mizrahim, og Shas ville utfordre dette hegemoniet gjennom 
opprettelsen av et eget parti og undervisningssystem. ${ }^{28}$

Etter Oslo-avtalen i I995 oppstod bevegelsen Mizrahi Democratic Rainbow, grunnlagt av venstreintellektuelle og aktivister i Israel. Medlemmene kjemper mot marginaliseringen og stigmatiseringen av mizrahim kultur, og prøver å framstille et alternativ til den eurosentriske, sionistiske identiteten. Dens alternative identitet skal være ikke-religiøs, demokratisk og pluralistisk. Denne bevegelsen understreker også viktigheten av å bygge bånd til palestinerne.

\section{Konklusjon}

Det har vist seg at Herzls opprinnelige løfte om likhet skulle forbli en utopisk tanke. Mizrahim fortsetter å lide under forhold skapt av den europeiske nasjonalistiske diskursen. ${ }^{29}$ Majoriteten har en langt lavere sosioøkonomisk posisjon enn jøder med europeiske forfedre. Tiår med masseimmigrasjon fra tidligere Sovjetunionen, økonomiske kriser knyttet til Israels globaliserte, neoliberalistiske økonomiske politikk, har marginalisert mizrahim ytterligere.

Økende klasseforskjeller og etniske skillelinjer er en stor utfordring for Israels interne stabilitet. Den israelske sosiologen Baruch Kimmerling hevder at hvis Israel en dag skulle løse konflikten med araberne, vil ashkenazi-mizrahi-problemet eksplodere. ${ }^{30}$ Et skritt i riktig retning er å anerkjenne at den rike arabisk jødiske historie og erfaring ikke utelukkende kan bli diskutert i europeisk jødisk terminologi. Holdningene som ligger til grunn for den eurosentriske nasjonale identiteten må utfordres og redefineres. Det er viktig å øke forståelsen for de arabiske jødenes historie og kultur for at de i større grad kan være aktivt med på å skape et mer rettferdig Israel.

\section{$\cdot f \cdot$}

I Denne artikkelen handler om ikke-europeiske jøders erfaringer, og tar ikke for seg den europeisk jødiske samfunn og historie.

2 Zohar, Zion: «Sephardic \& Mizrahi Jewry: From the Golden Age of Spain to Modern Times». New York University Press, 2005.

3 Bernard Lewis: “The Pro-Islamic Jews”, Judaism, høst, I968, s. 4 OI.

4 Cohen, Mark R: "The Origins of Sephardic Jewry in the Medieval Arab World", i Zion Zohar (red): «Sephardic \& Mizrahi Jewry: From the Golden Age of Spain to Modern Times». New York University Press, 2005.

5 Stillman, N.A: «The Jews of Arab Lands». Philadelphia, I957.

6 Ibid. s. I49.

7 Ibid. s. 160.

8 Bernard Lewis: «The Jews of Islam». Princeton University Press, 1984.

9 Shokeid, M: «The Dual Heritage: Immigrants from the Atlas Mountains in an Israeli Village». Manchester University Press (utvidet versjon, Transaction Books), I97I/I985.

Io Mimuna kommer fra det hebraiske/aramenske ordet "mammon" som betyr "rikest" eller "fruktbarhet". Ordet stammer også fra det hebraiske ordet "emunah" som betyr "tro".

II Tzadik (flertall tzadikkim) er det hebraiske ordet for rettroende.

I2 Levy, Andre: "Playing for Control of Distance: Card Games between Jews and Muslims on a Casablancan Beach", American Ethnologist, vol. 26, nr. 3., I999, s. 632653.

I3 Shokeid, M: "Jewish Existence in a Berber Environment in Jewish Societies in the Middle East", i. Shlomo Deshen and Walter P. Zenner (red.) «Jewish Societies in the Middle East: Community, Culture, and Authority». University Press of America, I982, s. I07.

I4 Katzir, Yael: "Preservation of Jewish Ethnic Identity in Yemen: Segregation and Integration as Boundary Maintenance Mechanisms", Comparative Studies in Society and History, vol. 24, nr. 2, I982, s. 264-279.

I5 Shulewitz, Malka: «The Forgotten Millions: The Modern Jewish Exodus from Arab Land». Continuum International Publishing Group, 2000.

I6 Ahroni, Reuben: «Jewish Emigration from the Yemen 
I95I-98. soAs Centre for Near \& Middle Eastern Studies, 2005 .

I7 Shiblak, Abbas: Iraqi Jews: A history. Saqi books, 2005 s. 40.

I8 Ibid. s. 62.

I9 Sitert i Shiblak, Abbas: «Iraqi Jews: A history». Saqi Books.

20 Shulewitz, Malka: «The Forgotten Millions: The Modern Jewish Exodus from Arab Land». Continuum International Publishing Group, 2000.

20 Ibid.

2I Zohar, Zion: «Sephardic \& Mizrahi Jewry: From the Golden Age of Spain to Modern Times». New York University Press, 2005, s. 60-72.

22 Shiblak, Abbas: Iraqi Jews: A history. Saqi books.

23 Ibid. S.I28.

24 Stillman, N.A: “The Judeo-Arabic Heritage", i Zion Zohar (red): «Sephardic \& Mizrahi Jewry: From the Golden Age of Spain to Modern Times». New York University Press, 2005 .

26 Shoat, Ella: "The Invention of the Mizrahim" i Journal of Palestine Studies, vol.29, nr. I, I999, s. 5-20.

27 Shoat, Ella: "The Invention of the Mizrahim" i Journal of Palestine Studies, Vol.29, nr.I, I999, S. 5-20.

28 Zohar, Zion: «Sephardic \& Mizrahi Jewry: From the Golden Age of Spain to Modern Times». New York University Press, 2005 .

29 Yiftachel, Oren: "Ethnic Frontiers and Peripheries: Landscapes of Development and Inequality in Israel", Geographical Review, vol. 88, nr. 3, I998, s. 485-459.

30 Kimmerling, Baruch: "Boundaries and Frontiers in the Israeli Control System: Analytical Conclusions," i Brauch Kimmerling, (red.), «The Israeli State and Society: Boundaries and Frontiers. Suny Press, 1989. 